\title{
Microstructural Analysis of in vitro Nacre Formation on Shell Bead and Titanium by Cultured Mantle Tissue of Pearl Oyster, Pinctada fucata
}

\author{
Cheruvathoor Poulose Suja ${ }^{{ }^{*}}$, Vidya Jayasankar ${ }^{\dagger \dagger}$, Vasudevan Srinivasa Raghavan ${ }^{\dagger \dagger}$, and \\ Koncies Mary Bosco ${ }^{\dagger}$
}

Tuticorin Research Centre, ICARCentral Marine Fisheries Research Institute

Tuticorin, Tamil Nadu, India

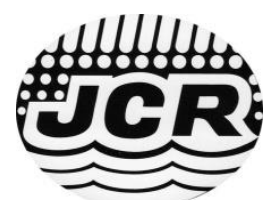

www.JCRonline.org

\begin{abstract}
Suja, C.P.; Jayasankar, V.; Srinivasa Raghavan, V., and Bosco, K.M., 2019. Microstructural analysis of in vitro nacre formation on shell bead and titanium by cultured mantle tissue of pearl oyster, Pinctada fucata. In: Jithendran, K.P.; Saraswathy, R.; Balasubramanian, C.P.; Kumaraguru Vasagam, K.P.; Jayasankar, V.; Raghavan, R.; Alavandi, S.V., and Vijayan, K.K. (eds.), BRAQCON 2019: World Brackishwater Aquaculture Conference. Journal of Coastal Research, Special Issue No. 86, pp. 164-169. Coconut Creek (Florida), ISSN 0749-0208.
\end{abstract}

Nacre, the inner iridescent layer of molluscan shells is an organic-inorganic composite material. The layered arrangement of platelet-shaped $\mathrm{CaCO}_{3}$ crystals and organic matrix in a brick-and-mortar structure makes it a strong, resilient, and iridescent material. In-vitro nacre formation on shell bead by the mantle tissue of the pearl oyster, Pinctada fucata has already been reported. The current study details a microstructural investigation and comparison of in vitro nacre deposition by the mantle tissue of pearl oyster, $P$. fucata on shell bead and titanium plates. Nacre platelets were observed by Scanning Electron Microscopy (SEM) and its $\mathrm{CaCO}_{3}$ composition was determined by Energy Dispersive X-Ray Spectroscopy (EDS) analysis on both shell bead and titanium plate. Nacre deposits displayed the typical lamellar brick and mortar" arrangement composed of aragonite platelets which form the "bricks" and organic matrix that forms the "mortar". Details of the microstructure of in vitro nacre formed by the mantle tissue of pearl oyster were elucidated for the first time by Atomic Force Microscopy (AFM). Further, the deposition of nacre on titanium proves its potential application as a suitable biomaterial in dental and bone implants, due to its biocompatibility towards regeneration.

ADDITIONAL INDEX WORDS: SEM, AFM, in vitro nacre, microstructure, titanium, biomaterial.

\section{INTRODUCTION}

Biomineralization in molluscs is a highly controlled process of hard tissue formation. Molluscan shell consists of inner aragonitic nacreous and outer calcitic prismatic layers. The crystal phase, shape, size, nucleation and growth of aragonite crystals are controlled by matrix proteins. Belcher et al. (1996) and Falini et al. (1996) described the crystal nucleation in molluscs. The mechanism of biomineralization of calcium in marine molluscs was studied by the culture of mantle for many years. The pearl oyster Pinctada fucata is one of the best studied species, both in vivo and in vitro. Kawai et al. (1981) first described the secretion of crystals in the explant culture of mantle tissue of pearl oyster. Dharmaraj and Suja (2004, 2006, 2010), Gong et al. (2008), Jayasankar et al. (2018), Suja (2003), Suja and Dharmaraj (2005), Suja and Lakshmana Senthil (2019) described characterization of crystals secreted by in vitro culturing of mantle tissue of the abalone, Haliotis varia, and pearl oyster, P. fucata, P. margaritifera and Pteria avicular.

The formation of nacreous layer is a potential model for the development of biomaterials. It has a wide variety of applications in the fields of crystal growth, tissue engineering,

DOI: 10.2112/ SI86-025.1 received 10 March 2019; accepted in revision 14 May 2019.

*Corresponding author: cpsuja@gmail.com

${ }^{\odot}$ Coastal Education and Research Foundation, Inc. 2019 nanotechnology and biomedical engineering. It can lead to novel thoughts for synthetic crystallization processes in materials science. Many earlier researchers have reported that nacre can stimulate bone cell differentiation and induce bone formation and, most importantly, nacre is degradable in vivo, making it a favourable material for the biological coating (Atlan et al., 1999; Liao et al., 2000; Mouries et al., 2002; Wang et al., 2005). Hence, coating an implant with nacre can make it more biocompatible and improve its diversity in application. Titanium is a biomedically important material which is used in orthopedic and dental applications. Coating the titanium based implants with nacre can still improve its biocompatibility and avoid graft rejection. Mayer (2005) pointed out that even though the toughening mechanisms involved in nacre have been the focus of significant research efforts in the past ten years, definite identification of the microstructural features leading to this performance are yet to be established. Atomic Force Microscopy (AFM) was used to understand the arrangement of crystal tablets in organic matrix in the nacre layer formation (Belcher et al., 1996; Li et al., 2004; Sarkariya et al., 1995). Evans et al. (2001) and Barthelat et al. (2006) revealed the presence of nanoasperities on the surface of the tablets in various densities, heights and shapes. Rosseau et al. (2005) used Scanning Electron Microscopy and Atomic Force Microscopy to understand the multiscale ordering of Pinctada maxima nacre and the role of the organic matrix in its structure. 

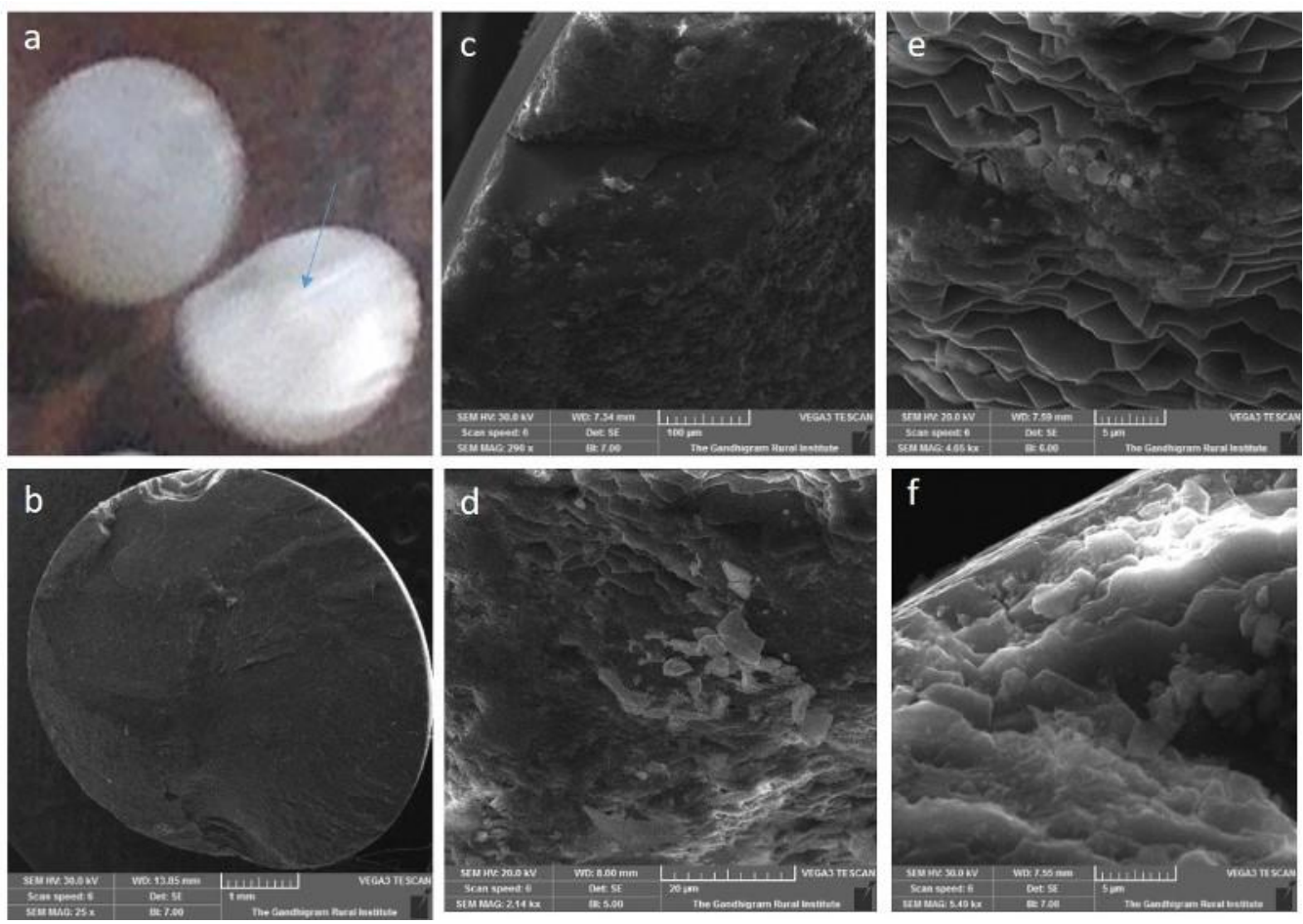

Figure 1. a) Photograph of the bead showing luster marked by an arrow, b) SEM image of the complete half bead surface, c) Edge of the half bead showing the stacking of aragonite layers sandwiched between organic layers, d) Deposits of crystal tablets, e) Lamellar nacre layers, f) Additional layers of crystal tablets seen under higher magnification.

The current study details the microstructural characterization of in-vitro nacre deposition by the mantle tissue of pearl oyster, $P$. fucata on shell bead and titanium plates. This study aims to prove the deposition of nacre over a biocompatible material, titanium through in-vitro culture of mantle tissue.

\section{Sample Collection}

\section{METHODS}

The animals were collected from Punnakayal Landing Centre, Gulf of Mannar with Longitude of $78^{\circ} 09^{\prime} 70^{\prime \prime}$ to $78^{\circ} 11^{\text {' }}$ 90 " E and Latitude of $08^{\circ} 47^{\prime} 20^{\prime \prime} \mathrm{N}$. The mantle tissue of the animal was dissected and processed as described by Suja and Dharmaraj (2005).

\section{Media Preparation and Inoculation}

The medium was prepared by dissolving $0.8 \mathrm{~g}$ of Agar (Hi Media) in $57.2 \mathrm{ml}$ of deionised water and $25 \mathrm{ml}$ of supplementary salt solutions and autoclaved at $121^{\circ} \mathrm{C}$ for 20 minutes. Culture medium containing 10x M199 (2 ml), FCS (10 $\mathrm{ml}), 5 \%$ lactalbumin hydrolysate $(5 \mathrm{ml}), \mathrm{NaHCO}_{3}(0.7 \mathrm{ml})$ and $0.1 \mathrm{~g} / \mathrm{ml}$ kanamycin $(0.1 \mathrm{ml})$ was prepared aseptically. This prepared medium was mixed with agar and $5 \mathrm{ml}$ of this medium was added to each flask. Sterile $5 \mathrm{~mm}$ titanium sheet and half shell beads of $4 \mathrm{~mm}$ were inoculated in this semi-solid medium. The processed explants were inoculated on one side of these implants for nacre coating studies.

\section{Scanning Electron Microscopy and Energy Dispersive X-ray Spectroscopy}

The control and experimental samples in the organ culture medium were taken for analysis. The samples were air-dried and coated with gold by ion-sputtering (JEOL-JFC1200E), and observed by Scanning Electron Microscopy (SEM) (TESCAN Vega3) and analyzed by an Energy Dispersive X-ray Spectroscopy (EDS) microanalyser (EDS, New Jersey, USA).

\section{Atomic Force Microscopy}

Atomic Force Microscope (AFM) (Nanosurf, Easyscan2, Switzerland) was used to image the surface topography of the experimental samples on the flat surface of shell bead and titanium sheet in operating mode with static force. The scan size of the image ranged between $2 \mu \mathrm{m}$ and $25 \mu \mathrm{m}$.

\section{RESULTS}

The mantle tissue liberated cells and it grew over and around the bead and nano layers of nacre were deposited. Out of four beads and four titanium sheets, one bead and one titanium sheet showed visible iridescence in the culture plate after four months and other beads showed slight change of colour. The experimental beads and titanium sheet were harvested after five months for characterization and the shining pieces were subjected to AFM, SEM and EDS analysis. The surface topography by AFM clearly revealed the deposition of nacre by the mantle cells over the shell bead and titanium sheet. 

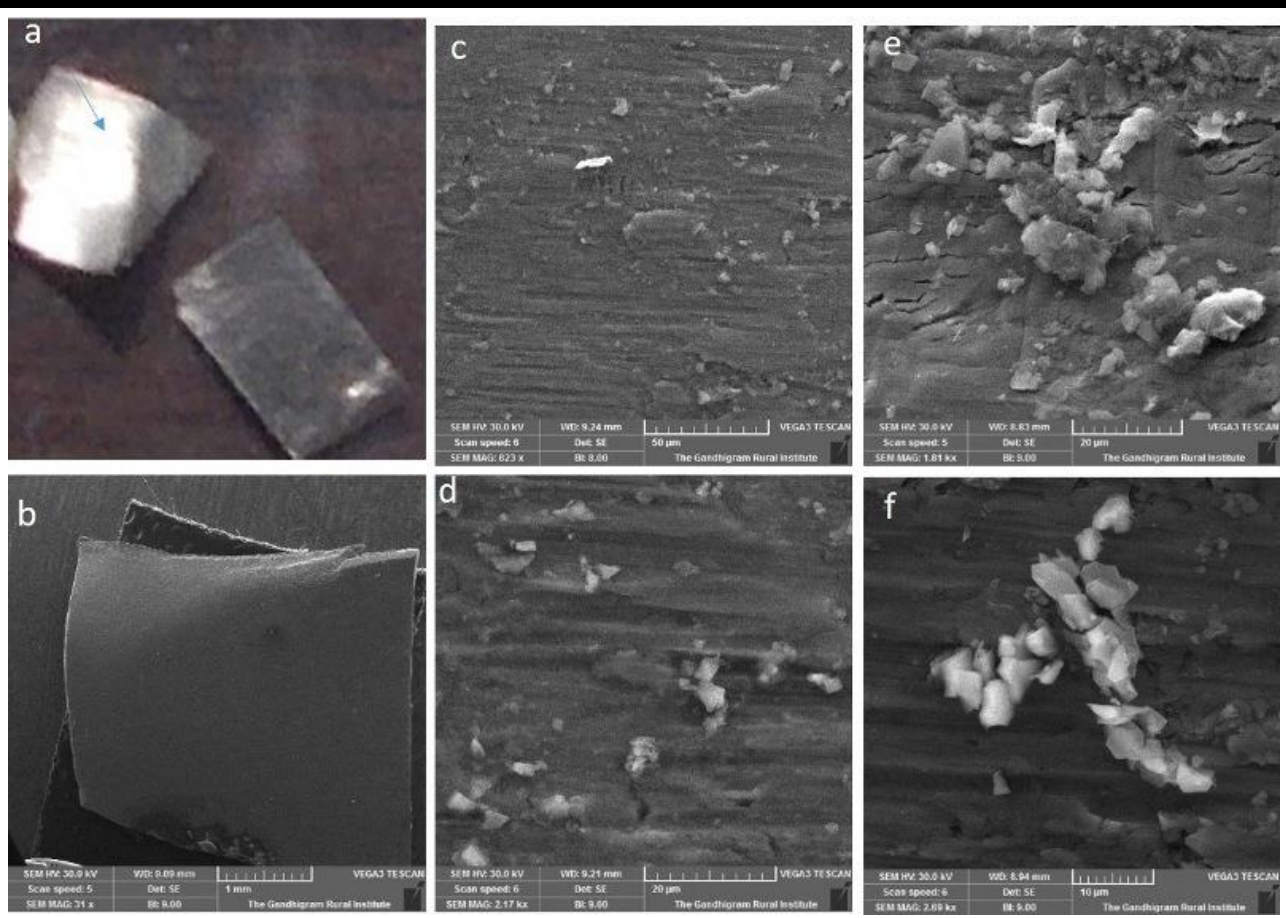

Figure 2. a) Photograph of the titanium sheet showing luster marked by an arrow b) SEM image of titanium surface, c) Calcium carbonate crystals scattered all over a wide area, d) Individual crystals deposited over the titanium sheet, e) Group of crystals over the titanium sheet, f) Hexagonal aragonite crystals over the sheet.

Nanograins which are the basic building blocks of nacre were observed on the surface of the experimental samples.

\section{Scanning Electron Microscopy}

The nacre deposition over the half bead and titanium was analysed by SEM. The complete bead surface subjected to SEM analysis is shown in Figure 1. The SEM results of half bead indicated that there was continuous growth of nacre throughout and nacre coating was formed over the flat surface. The typical brick-and-mortar formation, characteristic of nacre was visible under SEM. The edge of the half bead shows the stacks of aragonite layers sandwiched between organic layers. The bead revealed the regions where there are extra depositions of crystal tablets. The lamellar layer arrangement was more clearly visible in the micrograph. The SEM images of the titanium sheet did not show a complete brick and mortar formation (Figure 2). However, the deposition of crystals was seen clearly. Calcium carbonate crystals were seen scattered over a wide area. Individual crystals and groups of crystals were noticed in some regions of the experimental titanium sheet. The titanium was seen to be coated with hexagonal aragonite crystals.

\section{Energy Dispersive X-ray Spectroscopy}

Deposition of calcium carbonate on the experimental samples was confirmed by EDS analysis and compared with the controls. Figure 3a shows the calcium peak with $24.54 \%$ of calcium in experimental shell bead and Figure $3 \mathrm{~b}$ shows the EDS with only $5.64 \% \mathrm{Ca}$ in Control bead. The experimental sample of titanium with calcium carbonate group of crystals when analysed by EDS showed $27.76 \%$ of calcium (Figure 3c). The deposition of calcium on titanium was further proved when the control piece of titanium subjected to EDS did not show any peak of $\mathrm{Ca}$, but showed only $\mathrm{Ti}$ and $\mathrm{O}$ groups (Figure $3 \mathrm{~d}$ ).

\section{Atomic Force Microscopy}

The surface topography by AFM clearly revealed the deposition of nacre by the mantle cells when the control half bead and experimental bead and titanium piece topography were compared under AFM. Figures $4 \mathrm{a}$ and $4 \mathrm{~b}$ show 2D and 3D pictures which confirm the formation of nacre over bead and titanium sheet. Nanograins were observed on the surface of the experimental pieces which are the basic building blocks of nacre. The increase in the vertical (roughness) and lateral (correlation length) grain size as the indication of deposition was clearly visible in AFM results. Nanoasperities inside individual platelets were confirmed by the grooves and valleys in the figures in the scanned topography.

\section{DISCUSSION}

The present work was aimed at studying the formation of biomineralization over the shell bead and the titanium sheet by using mantle tissue of $P$. fucata and to study the microcrystalline structure of the formed layer. Previous studies have shown that primary explant cultures from the mantle were capable of biomineralization. But in this study, crystal formation over the bead and titanium sheet was analyzed. 


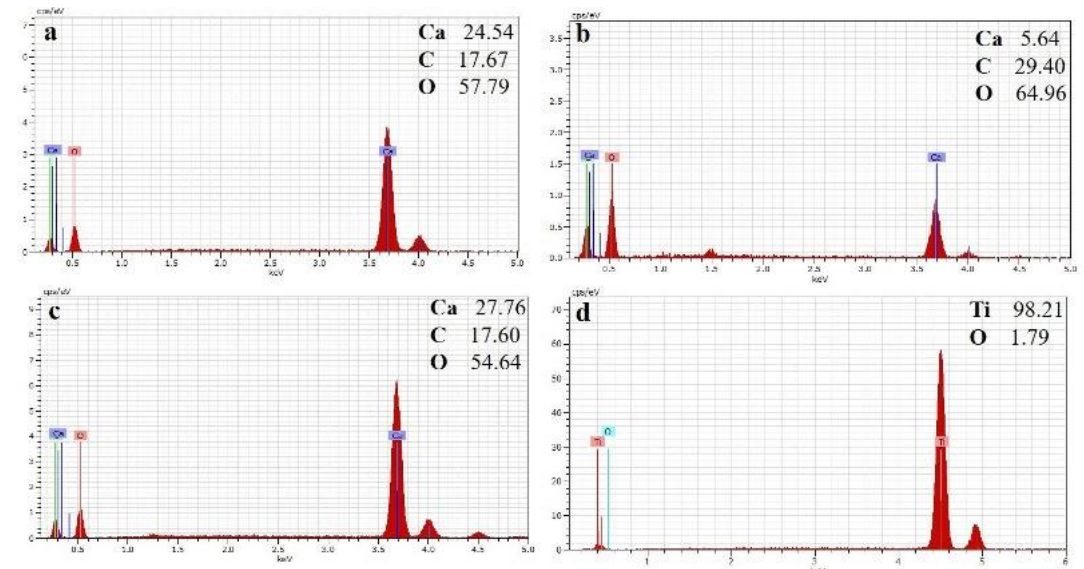

Figure 3. EDS result of control and experimental shell bead and titanium sheet a) EDS of experimental shell bead, b) EDS of control shell bead, c) EDS of experimental titanium sheet, d) EDS of control titanium sheet.

(a)
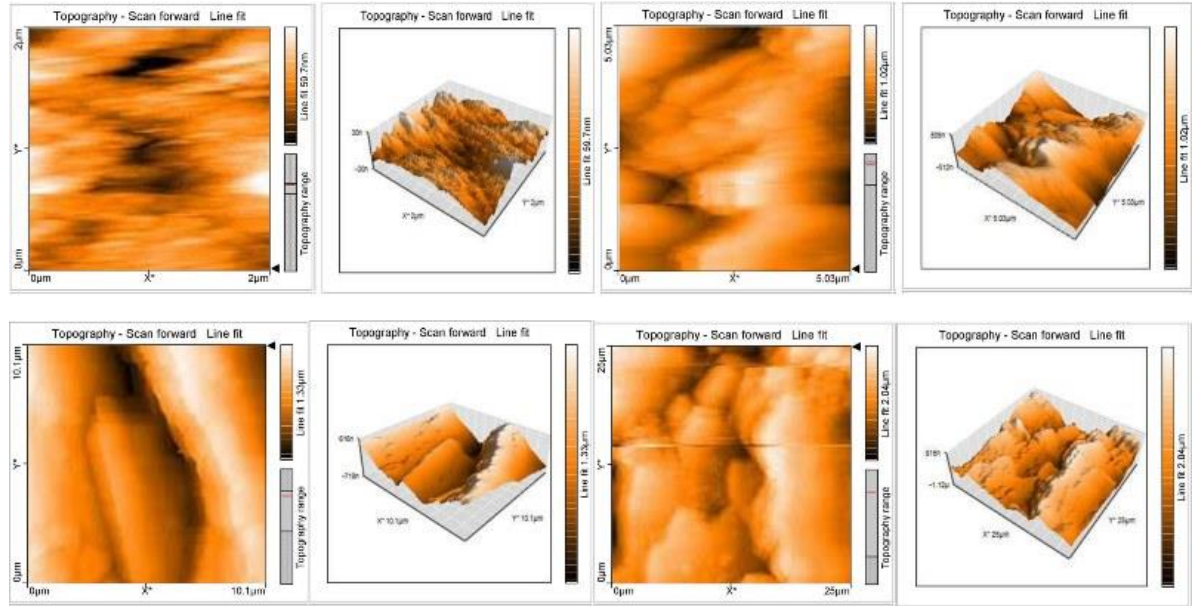

(b)
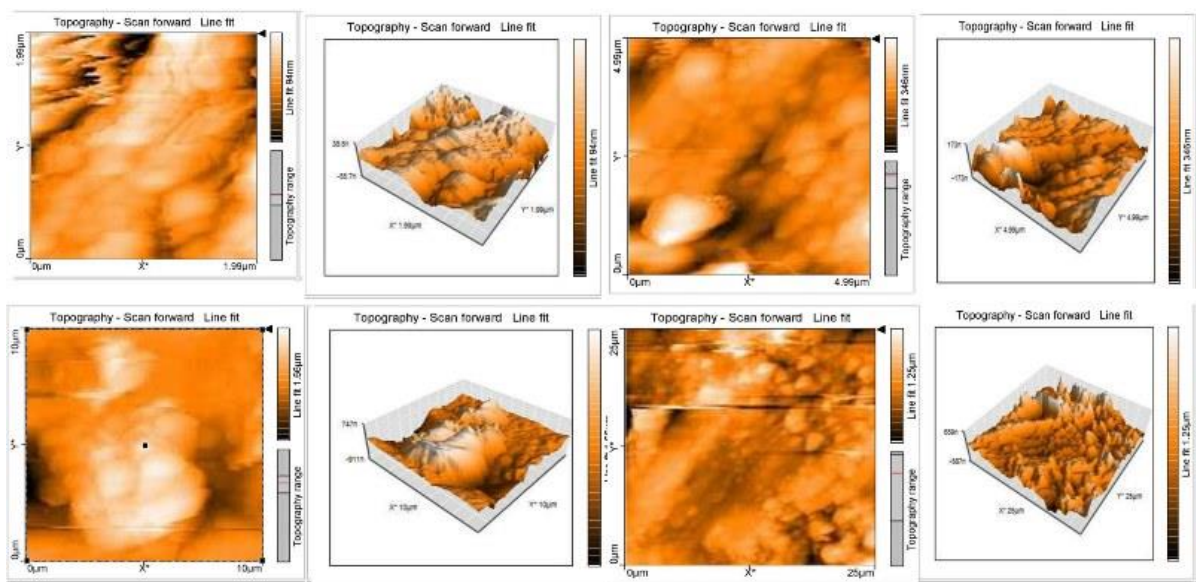

Figure 4. Atomic Force Microscopy scans from different areas showing the topography of nacre deposition on a) Shell bead, b) Titanium. 
Wada et al. (1985) reported that the small spherulite of calcium carbonate grew after four days of operation. Crystal nucleation over the organic matrix and the joining of these crystals results in lamellar formation over the bead. Suja and Dharmaraj $(2006,2010)$ and Suja and Lakshmana Senthil (2019) reported the lamellar formation of nacre by the in vitro mantle tissue culture of $P$. fucata and Jayasankar et al. (2018) reported the lamellar formation by in vitro culture of mantle cells of $P$. margaritifera. In this study, the lamellar formation was clearly visible on the shell bead with the mantle tissue of $P$. fucata and a group of crystals was also noticed on the titanium sheet. Morphology and size of the crystals varied at different areas of the same experimental bead and titanium.

Many studies have shown that amorphous calcium carbonate plays a crucial role in the formation of mineralized tissues (Miyazaki et al., 2010). Aragonite is the purest form of calcium carbonate which is the same as that of calcite (Addadi et al., 2006). The shell bead and titanium pieces were analyzed by EDS and the deposition of nacre was proved as calcium carbonate. The percentage of calcium was $24.54 \%$ and $27.76 \%$ on shell bead and titanium respectively. Absence of calcium on control titanium piece confirmed the nacre crystal deposition by in vitro biomineralization of mantle tissue of $P$. fucata. The percentage of calcium over the lamellar formation was not too high. This confirms the presence of organic matrix as suggested by Liu et al. (2012).

The mantle tissue is responsible for shell formation and secretes a matrix complex that includes proteins, polysaccharides and lipids. It has been suggested that the insoluble proteins provide the framework and mechanical properties of the shell, whereas the soluble proteins are involved in crystal nucleation and growth (Falini et al., 1996). The outer calcite prismatic layer is always related to the proteins secreted from the outer epithelial cells of the edge of the mantle, whereas the inner aragonite nacreous layer is related to the proteins of the pallial region (Liang et al., 2015).

Li et al. (2004) suggested that the aragonite tablets are actually composed of nanograins from atomic force microscopy observations. Belcher et al. (1996) reported that the biomineralization of the tablets leaves some soluble proteins within the tablets, as intra-crystalline inclusions. Rosseau et al. (2005) reported that the organic matrix is organized in the form of a 'foam' with very thin walls and closed cells. The mineral nanograins are thus encapsulated inside the organic framework (vesicle). In this study the nanograins were seen encapsulated by the organic matrix as visible by dark and light areas. In the present study on flat surface of shell bead and titanium piece, nanograins were visible at varying densities, heights and shapes as reported by Barthelat et al. (2006). The increase in the vertical (roughness) and lateral (correlation length) grain size as the indication of deposition rate, was clearly visible in AFM results as reported by Mirazaee et al. (2012). Cuif et al. (2012) studied the surface topography of nacre by AFM and reported the changes in surface slopes.

The structure of nacre and its application for biomaterial studies due to its well-defined lamellar organization has been reported by many researchers. The in vitro deposition of nacre layer over shell bead and the titanium will open up a new area of research for dental and bone implants. Atlan et al. (1999) already proved the biocompatibility of nacre in in vivo studies carried out on adult sheep. Wang et al. (2005) implanted titanium screws and flat sheets into the epithelial mantle pearl sacs of a fresh water bivalve (Hyriopsis cumingii) by replacing the pearls and got nacre coating after 45 days. They suggest that it is possible to fabricate a biologically active and degradable, and mechanically tough and strong nacre coating on titanium dental implant by this novel coating technology. By this analysis, it was proved that the mantle cells of $P$. fucata are capable of secreting crystals under in vitro conditions over the shell beads and the titanium sheet. The role played by the microenvironment on the formation of aragonite and calcite crystals needs further investigations.

\section{CONCLUSION}

The microstructure of in vitro nacre formed by the mantle tissue of pearl oyster was elucidated for the first time by Atomic Force Microscopy (AFM). The coating of in vitro nacre on titanium was demonstrated for the first time by SEM, EDS and AFM. The deposition of in vitro nacre on titanium proves its potential application as a suitable biomaterial in dental and bone implants, due to its biocompatibility towards regeneration.

\section{ACKOWLEDGMENTS}

We wish to thank the Director, the Head of Marine Biotechnology Division and the Scientist-in-Charge, Tuticorin Research Centre of the ICAR-Central Marine Fisheries Research Institute for facilitating the work.

\section{LITERATURE CITED}

Addadi, L.; Joester, D.; Nudelman, F., and Weiner, S., 2006. Mollusk shell formation: A source of new concepts for understanding biomineralization processes. Chemistry European Journal, 12, 980-987.

Atlan, G.; Delattre, O.; Berland, S.; Lefaou, A.; Nabias, G.; Cot, D., and Lopez, E. 1999. Interface between bone and nacre implants in sheep. Biomaterials, 20, 1017-22.

Barthelat, F.; Li, C.; Comi, C., and Horacio, D., 2006. Mechanical properties of nacre constituents and their impact on mechanical performance. Journal of Materials, 21, 1977-1986.

Belcher, A.M.; Wu, X.H.; Christensen, R.J.; Hansma, P.K.; Stucky, G.D., and Morse, D.E. 1996. Control of crystal phase switching and orientation by soluble mollusc-shell proteins. Nature, 381, 56.

Cuif, J.; Dauphin, Y.; Nehrke, G.; Nouet, J., and Perez-Huerta, A., 2012. Layered growth and crystallization in calcareous biominerals: Impact of structural and chemical evidence on two major concepts in invertebrate biomineralization studies. Minerals, 2, 11-39.

Dharmaraj, S. and Suja, C.P., 2004. Pearl production techniques through tissue culture in the Indian pearl oyster (Pinctada fucata) and in the abalone (Haliotis varia) and other pearl producing molluscs. Indian patent No.,1987/DEL/04 (IPR-Indian Council of Agricultural Research).

Dharmaraj, S. and Suja, C.P., 2006. Pearl production techniques through tissue culture in the Indian pearl 
oyster (Pinctada fucata) and in the abalone (Haliotis varia) and other pearl producing molluscs. International Patent No., PCT/IB 2006/003299.

Dharmaraj, S. and Suja, C.P., 2010. In-vitro pearl production using marine organisms. US Patent 2010/0055787 A1.

Evans, A.G.; Suo, Z.; Wang, R.Z.; Aksay, I.A.; He, M.Y., and Hutchinson, J.W., 2001. A model for the robust mechanical behavior of nacre. Journal of Biomaterials, 16,2475

Falini, G.; Albeck, S.; Weiner, S., and Addadi, L., 1996. Control of aragonite or calcite polymorphism by mollusk shell macromolecules. Science, 271, 67-69.

Gong, N.; Ma, Z.; Li, Q.; Li. Q.; Yan, Z.; Xie, L., and Zhang, R., 2008. Characterization of calcium deposition and shell matrix protein secretion in primary mantle tissue culture from the marine pearl oyster Pinctada fucata. Marine Biotechnology, 10, 457-465.

Li, X.D.; Chang, W.C.; Chao, Y.J.; Wang, R.Z., and Chang, M., 2004. Nanoscale structural and mechanical characterization of a natural nanocomposite material: The shell of red abalone. NanoLetters, 4, 613.

Liang, J.; Xu, G.; Xie, J.; Lee, I.; Xiang, L.; Wang, H.; Zhang, G.; Xie, L., and Zhang, R., 2015. Dual Roles of the Lysine-Rich Matrix Protein (KRMP)-3 in Shell Formation of Pearl Oyster, Pinctada fucata. PLoS One, 10 (7), e0131868.

Liao, H.; Mutvei, H.; Sjostrom, M.; Hammarstrom, L., and Li, J., 2000. Tissue responses to natural aragonite (Margaritifera Shell) implants in vivo. Biomaterials. 21, 457-468.

Liu, X.; Li, J., and Xiang, L., 2012. The role of matrix proteins in the control of nacreous layer deposition during pearl formation. Proceedings of Royal Society of Biological Sciences, 279, 1000-1007.

Marthe Rousseau; Evelyne Lopez; Philippe Stempflé; Marcel Brendlé, and Loïc Franke, 2005. Multiscale structure of sheet nacre. Biomaterials, 26, 626-631.

Mayer, G., 2005. Rigid biological systems as models for synthetic composites. Science, 310, 1144.

Miyazaki, Y.; Nishida, T.; Aoki, H., and Samata T., 2010. Expression of genes responsible for biomineralization of Pinctada fucata during development. Biochemistry and Molecular Biology of Comparative Biochemistry and Physiology, 155, 241-248.

Mouries, LP.; Almeida, MJ.; Milet, C.; Berland, S., and Lopez, E., 2002. Bioactivity of nacre water-soluble organic matrix from the bivalve mollusk Pinctada maxima in three mammalian cell types: fibroblasts, bone marrow stromal cells and osteoblasts. Biochemistry and Molecular Biology of Comparative Biochemistry and Physiology, 132, 217-29.

Sarikaya, M. and Aksay, I.A., 1995. Biomimetics: Design and Processing of Materials. Woodbury, N.Y., AIP Press.

Suja, C.P. and Dharmaraj, S., 2005. In vitro culture of mantle tissue of the abalone Haliotis varia Linnaeus. Tissue and Cell, 37, 1-10.

Suja, C.P. and Lakshmana Senthil, 2019. Organ culture of mantle tissue of different pearl producing molluscs. In: Suja, C.P. (ed.), In vitro Pearl Culture Techniques: A Biotechnological Approach. CMFRI Special Publication No. 131, pp. 34-53.

Suja, C.P., 2003. Mantle tissue culture of abalone, Haliotis varia Linnaeus, Manonmanium Sundaranar University, $\mathrm{Ph}$. D dissertation, 145p.

Suja, C.P., 2019. In vitro Pearl Culture Techniques: A Biotechnological Approach. CMFRI Special Publication No. 131, pp. 60.

Wada, K., 1985. Growth of CaCO3 crystals in bivalve shell mineralization. Japan Journal of Crystal Growth, 12, 5770.

Wang, X.; Xie, L., and Wang, R., 2005. Biological fabrication of nacreous coating on titanium dental implant. Biomaterials. 26, 6229-6232.

Watabe, N., 1983. Mollusca: Shell. In: Richards, K.S. (ed.), Biology of the Integument.Vol. 1. Invertebrates. (in Press). Springer-Verlag, New York/Berlin. 